\title{
ENHANCING A LEARNING MANAGEMENT SYSTEM TO TRACK ATTENDANCE USING RFID
}

\author{
Kamal Hingorani, Alabama State University, khingorani@alasu.edu \\ Bob McNeal, Alabama State University, bobmcneal@alasu.edu \\ Darius Carlton, Alabama State University, dcarlton@alasu.edu \\ Nasrin Askari-Danesh, Alabama State University, ndanesh@alasu.edu
}

\begin{abstract}
Over 95 percent of institutes of higher education in the U.S. have a learning management system (LMS) in place. Blackboard (BB) is one of the most widely used LMS and has a building block (freeware) that provides the ability to manually record and track attendance of students in different courses. This paper describes a RFID system that was developed in-house that automated the process of recording students' attendance in the existing attendance system on Blackboard.
\end{abstract}

Keywords: Information Technology (IT), RFID, Attendance and Information System

\section{INTRODUCTION}

Student class attendance at the university and college level has been a subject of concern for many years. Poor class attendance is an issue in higher education in a number of countries such as the US [7], the UK [8], Taiwan [3], Hong Kong [4], Scotland [10], and South Africa [12]. For example, Newman-Ford et al [8] studied attendance compared to performance (617 students in 3 compulsory modules) at the University of Glamorgan, UK. Although attendance dropped off as the semester progressed, the more students attended class, the higher the probability of higher grades and less chance of failing. Paisey and Paisey [10] found a strong positive correlation (.58) between overall performance and attendance in an accounting module at a Scottish University. The correlation was significant at the $1 \%$ level. Other researchers have identified similar correlation statistics. Crede, Roch, and Kieszcynka [5] performed a meta-analytic review of the class attendance and performance relationship based on literature published between 1927 and 2009, The results demonstrated that class attendance is highly correlated with grades and Grade Point Average (GPA), even more that that found in meta analytic reviews that included SAT scores, study habits, and study skills. They concluded that the evidence was so strong that significant improvement in grades and reduced failure rates could result from an increased focus, by Colleges and Universities, on improving class attendance rates.

In addition to the importance of student performance and retention, class attendance has an impact on retention and graduation. As demonstrated in the literature, the more that students miss classes, the higher the chance of not passing. As a result, failing a course can delay graduation which results in more tuition paid, delayed entry into the job market, and lower lifetime earnings. Also, since financial aid is tied to the number of hours a student has attempted, student financial aid can be affected. Funding for public universities is often linked to graduation rates and time to complete graduation. An increase in poor performance impacts funding with tax dollars which clearly impacts taxpayers [5].

The positive relationship between class attendance and performance has resulted in some universities adopting required attendance policies with penalties for non-attendance. In other universities, where there is no attendance policy, instructors have policies that either penalize students for non-attendance or reward them with points assigned to their attendance record for the course. However, tracking student attendance and maintaining paper based records is a cumbersome task that takes up class time and adds to the class management burden. Disadvantages of paper based systems include students not signing in, signing in another student, unreadable signatures, and data management. Students who are inclined to skip classed know that manual attendance (i.e., calling roll, etc.) can be manipulated in their favor. In the recent past, the problems associated with gathering and maintaining paper based attendance records has been overcome through the use of technology. Although some claim that electronic systems can be manipulated, students seem to view these systems as more foolproof. In other words, students see fewer ways to manipulate attendance systems based on technology [8]. 


\section{Issues in Information Systems}

Volume 14, Issue 2, pp.313-318, 2013

\section{ELECTRONIC ATTENDANCE SYSTEMS}

In 2007, Baylor University developed a module that could be used in conjunction with a Learning Management System (LMS) such as BlackBoard (BB) [1]. An instructor records student attendance for each class period but rather than recording the data on paper enters it into BB electronically. The positive aspect of the module is that it eliminates the manual paper process although it does not replace the time consuming process of calling a roll. However, it does have reporting features and allows attendance data to be captured in a centrally located database. For example, attendance data can be used for improving retention and graduation rates. Another system, UniNanny, uses a microchip in a fob. The instructor brings a small baton to class and students touch their fob to the baton and then pass it around. However, this system is similar to the process of students signing in and has many of the same weaknesses.

Systems based on Radio Frequency Identification (RFID) provide another method of recording attendance, although the use of these systems has raised issues of privacy and surveillance at some universities. Northern Arizona University (NAU) implemented a university-wide RFID attendance system for large classes. However, this process generated negative press and controversy [3,6]. Dicle and Levendis [2] developed and implemented a RFID system using low frequency RFID proximity readers and tags (keyfobs). The RFID reader in their system connected to a PC in the classroom through a USB port. The system issued keyfobs to students and also recorded attendance on a macro-enabled Excel workbook. Their system had one strong disadvantage-the system could not record attendance if another program was started on the PC. The advantages of an RFID system is that (i) it offers the potential to eliminate the manual process of gathering attendance data and record keeping, (ii) eliminates the tedious classroom process of roll taking, and (iii) most importantly encourages class attendance when coupled with an institution, college, or course required attendance policy.

This paper describes an RFID attendance system that uses a classroom computer and low frequency proximity RFID readers with an RS-232 (Serial Port) interface. This system allowed attendance to be recorded even while other programs were running on the computer system. The attendance was captured on a SQL Server database. The system has been in use for over three semesters in a College of Business at a south-eastern university with complete buy in from all faculty members. During Spring 2013, the system recorded over 23, 000 attendance values for classes taught in the college.

\section{ALABAMA STATE UNIVERSITY'S COLLEGE OF BUSINESS IMPLEMENTATION}

In May of 2009, Alabama State University's Board of Trustees adopted a new attendance policy. This was due to Faculty Senate and university administration concerns about poor class attendance. The new policy allowed students one unexcused absence for each credit hour of a course (i.e., three unexcused absences allowed for a three hour course). The policy provided an opportunity for a student with valid documentation (i.e., a doctor's office document) to obtain an official university excuse from the Office of Student Affairs. In the event of three or more unexcused absences, the student's final can be reduced or a grade of " $F$ " can be assigned. In addition, students do not have the opportunity to makeup missed assignments, exams, etc. until they have provided an official university excuse.

Course instructors are charged with maintain accurate records, but no provision was included for improvement over manual processes. However, beginning with the Fall 2010 semester's upgrade of BB, faculty could replace record keeping with BB's online attendance block. Even so, this procedure still required class time to capture attendance and enter the data. During the Spring 2012 semester, the Office of the Provost asked the College of Business to conduct a pilot study using the RFID system described previously. The system was tested during the summer 2012 semester with no problems identified and implemented in the Fall 2012 semester.

The RFID attendance system required a PC with a RS232 port with access to the SQL Server database. The RFID reader that used for this system was the Cytron- RB-Cyt-63- RFID reader shown in Figure 1. This reader is a low cost solution for a passive RFID tag reader that supports the $125 \mathrm{KHz}$ RFID passive tag. It operates on a 9600 baud rate through RS232 standard interface. The reader is powered through a separate USB connection. This reader costs $\$ 45$ and is shown in Figure 1. Cytron's $125 \mathrm{KHz}$ RFID passive Tag (Key Fob), illustrated in Figure 2, was used with the reader. The cost of the tag is less than $\$ 1.00$ and is programmed with a unique 32-bit ID (10 digits), but it is not re-programmable. 


\section{Issues in Information Systems}

Volume 14, Issue 2, pp.313-318, 2013
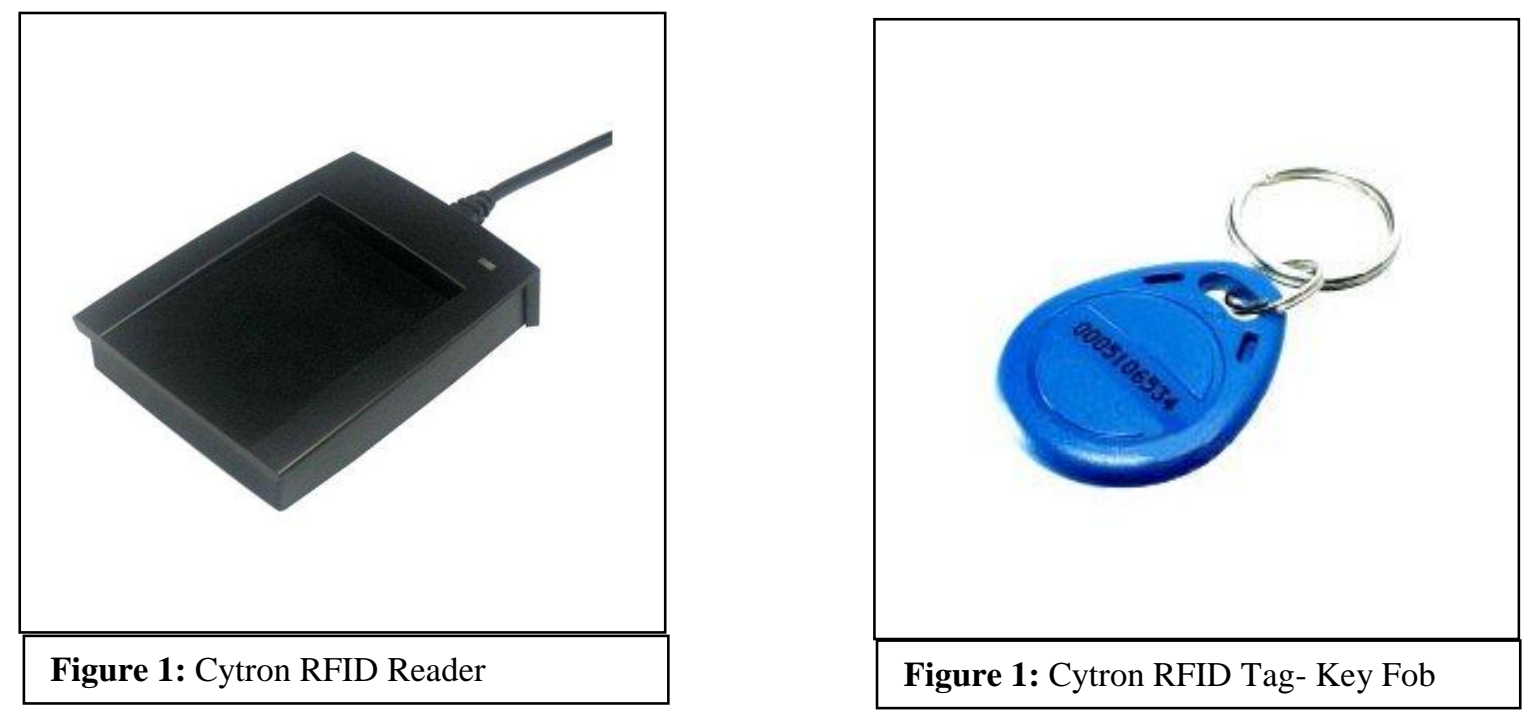

Each student is assigned a free Key Fob. They are expected to keep the key until graduation. A replacement is made available to students for a $\$ 2.00$ fee. For issuing a key to a student, a small VB.Net program records the 32-bit id for the students' user id and student name in the database. A VB.Net program for reading the passive RFID tag was also created. It reads the unique 32-bit id of the passive tag, looks up the user-id, and the date record for the course and date. The program then inserts the attend value along with the user id and date record in the AttendRecs table.

Each course instructor is expected to run the VB.net program, which is password protected, on the classroom computer. Initializing the program produces an interface (Figure 3) which requires that the instructor select their name from a drop down box, and then select the class for which attendance is being recorded. After connecting the system and as students enter the classroom, they scan their RFID tags. On every scan the name of the student is displayed on a list box. This prevents a student from scanning another student's key and also helps faculty learn the name of their students. The time of the scan is also recorded. The program automatically shuts down after 20 minutes of operation. Class begins as soon as the entire process is complete. Future plans include modifying the VB program so that a student's attendance record for the class is recorded as "Late" when the student arrives ten minutes after class has started.

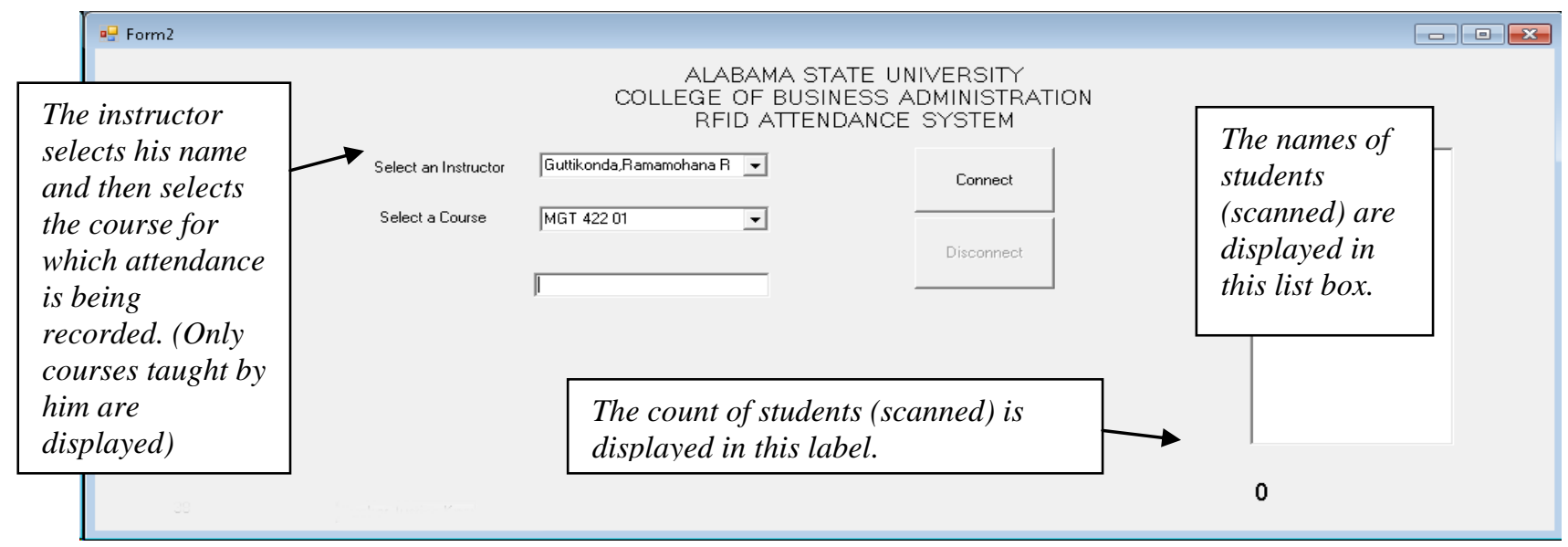

Figure 2: The RFID Attendance System Interface 


\section{ONLINE ATTENDANCE SYTEM IN BLACKBOARD}

The online attendance module for BlackBoard was developed by Baylor University (BU) and is available for installation as a freeware, although BB does not provide technical support for the shareware [1]. BB provides the following description of the module:

"This building block is designed to help instructors using Blackboard as a supplement to traditional face-to-face classes, track and mark attendance for a course while also allowing the student to keep track of their attendance. The building block was designed to allow an instructor the capability to set-up class attendance by both dates for the term and days of the week for which the class meets. Also attendance can be marked by date or by seating chart. The options for marking attendance in this system are Present, Absent, Late, Excused or Unexcused. The student view allows student to see how the instructor marked attendance for each day and gives the student a summary total for each marking option..." [1]

The module developed by BU used JSP, resided on an SQL Server, and used three database tables as shown in Figure 4 below.

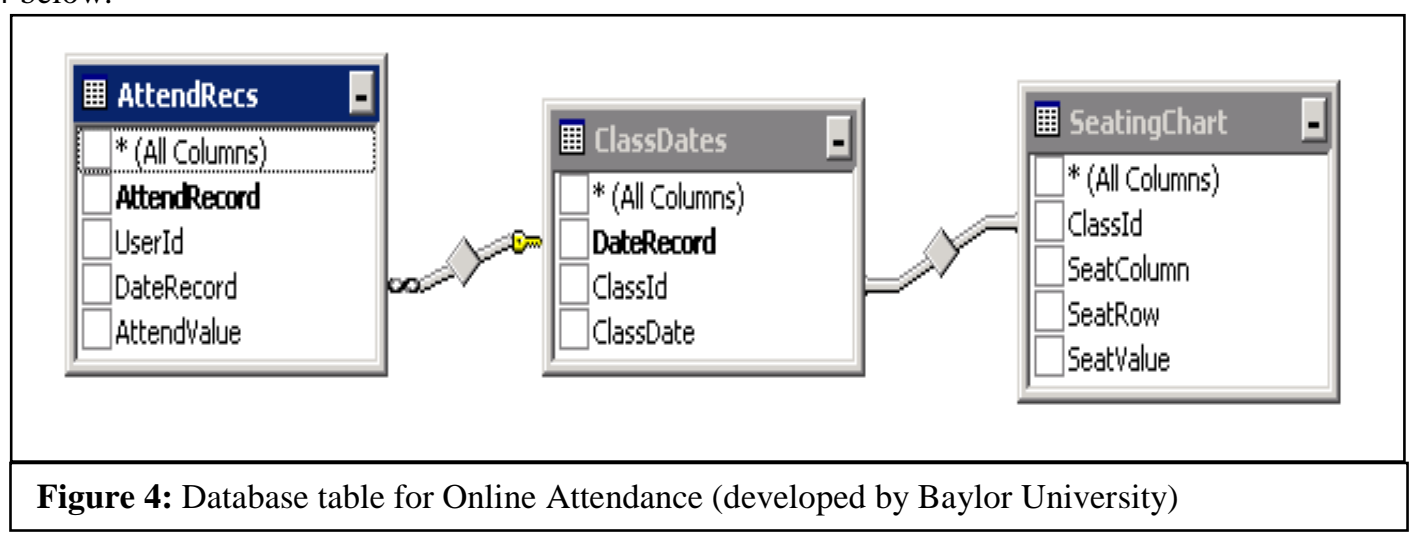

For a normal course, the start date, end date, and meeting days are required for populating the Class Date table. Each course has a unique classid and each student has a unique userid. For each course, the Class Dates table is populated by the instructor completing the input screen shown in Figure 5 below:

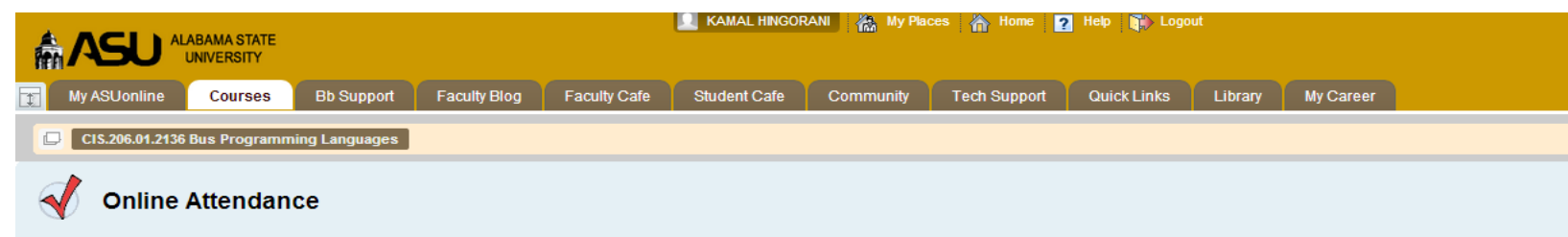

Return to Menu Add Individual Days Remove Individual Days

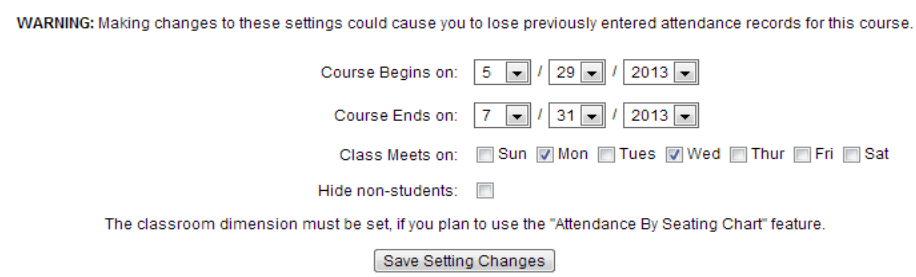

Figure 5: The On-Line Attendance-Setup screen in BB 
For the RFID enhancement two additional tables, Student name and Course Name \& ID were required. The seating chart capability in BB was not used by the program. The tables and the relationships of the four tables used by the RFID program are shown in Figure 6.

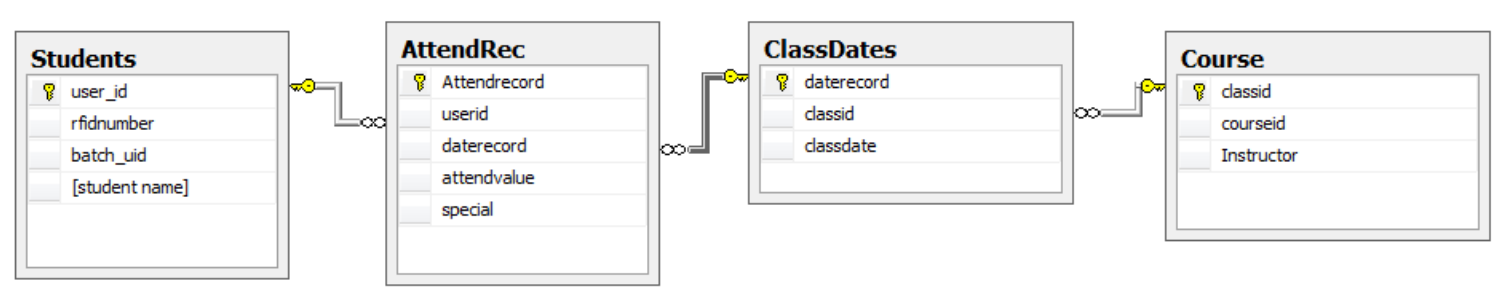

Figure 6: The Database tables used by the RFID program

\section{RESULTS}

One measure of the success of the system is demonstrated by its acceptance. All instructors adopted the program without objection. Over 23,000 attend values were recorded during the Spring 2013 semester. Resources required for purchasing the RFID readers and tags were minimal and within the budget allocation of the MIS department. Initial faculty (non-MIS) training presented a few minor problems such as selecting the wrong courses. However, as the Fall 2012 semester progressed, this problem disappeared.

Student acceptance of the RFID process was universal. Initially one student complained about privacy issues. However an explanation of the use of the data, as-well-as the low power of the RFID reader and tags cleared his misconceptions. Students generally keep the RFID tag attached to their apartment or auto keychain. Problems with lost RFID tags have been minimal.

We expected that implementation of the RFID attendance system would improve the level of class attendance. We conducted a comparison of attendance data, before and after implementation of the RFID system, using (International Business, MGT 460) and (Math for Business ECO 201). The results of this analysis were inconclusive. There are a number of factors that affect attendance and the impact of the RFID system on attendance can be assessed through a well-designed two-group randomized experiment.

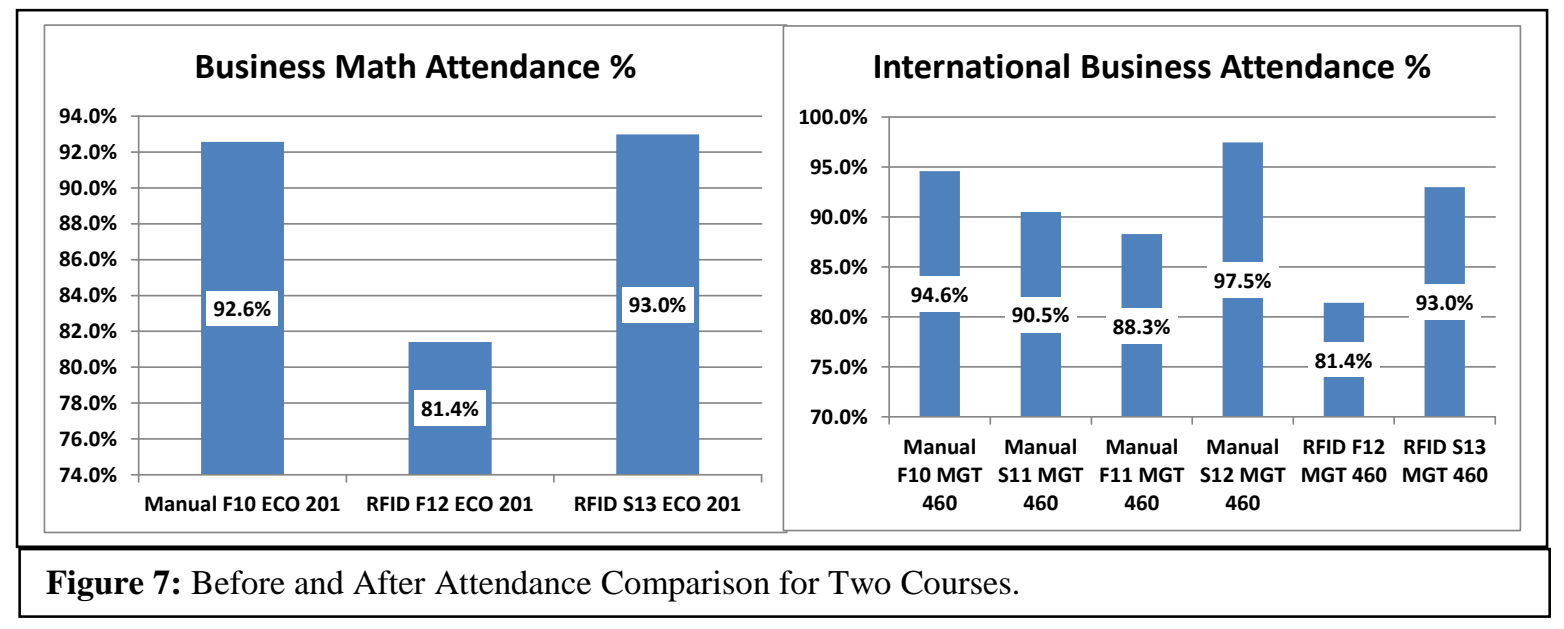

The primary purpose of implementing this process was to evaluate its feasibility in terms of reducing class time by replacing manual roll calling, improving the accuracy of data collection, and minimizing the course instructor's time in managing attendance data. A focus group with selected faculty members provided some evidence supporting the fact that the addition of the RFID system met all three of these objectives. 


\section{Issues in Information Systems}

Volume 14, Issue 2, pp.313-318, 2013

\section{CONCLUSIONS}

The implementation of an RFID attendance system can provide several benefits. Conversations with faculty indicate that implementing the RFID system reduced the class time required to collect attendance data, reduced the number of errors and streamlined the data management process. The RFID attendance system continues to be used in the College with great success.

\section{REFERENCES}

1. Anonymous (2009, August 19). Blackboard Building Blocks.com. Retrieved May 1, 2013 from http://www.blackboard.com/pages/popups/bldgBlocksPopupInfo.aspx? ExtensionID=10023

2. Alabama State University (May 2009). Class Attendance Policy. Retrieved June 10, 2013 from http://www.alasu.edu/download. aspx?id $=4969$.

3. Chen, J., \& Lin, T. (2008). Class attendance and exam performance: A randomized experiment. Journal of Economic Education. 39.3, 213-227. Summer.

4. Chong, T., Cheung, K., and Hui, P. (2009). Skipping economics classes: a case study from Hong Kong. Journal of Higher Education Policy and Management. 31 (1), 37 - 42. February.

5. Crede M., RochS. and Kieszczynka (2010). Class Attendance in College: A Meta-Analytic Review of the Relationship of Class Attendance with Grades and Student Characteristics. Review of Educational Research. 80 (2), 272 - 295. June.

6. Dicle, Mehmet F. and Levendis, John (2011), The DL-Attendance System: A 29ø Solution to Electronic Attendance (September 13, 2011). Available at SSRN: http://ssrn.com/abstract=1926847 or http://dx.doi.org/10.2139/ssrn.1926847.

7. Moore, R. (2003). Attendance and Performance: How important is it for students to attend class? Journal of College Science Teaching. 32. $367-371$.

8. Newman-Ford, L, Fitzgibbon, K., Lloyd, S., and Thomas, S. A large scale investigation into the relationship between attendance and attainment: a study using an innovation, electronic attendance monitoring system. Studies in Higher Education. 33 (6), 699 - 717. December.

9. O'Connor, M. (2010, May 24) Northern Arizona University to Use Existing RFID Student Cards for Attendance Tracking. RFID Journal. Retrieved May 1, 2013 from http://www.rfidjournal.com/articles/view?7628

10. Paisey, C. and Paisey, N. (2004). Student attendance in an accounting module - reasons for non-attendance and the effect on academic performance at a Scottish University. Accounting Education. 13 (Supplement 1), 39- 53. December.

11. RFID Attendance - Brilliant or Nuts? (2013) ZDNet Retrieved May 1, 2013 from http://www.zdnet.com/blog/education/rfid-attendance-brilliant-or-nuts/3902

12. Schalkwyk, S. Menkveld H. and Ruiters, J. (2010). What's the story with class attendance? First-year students: Statistics and Perspectives. South African Journal of Higher Education, 24 (4), 630 - 645.

13. UA Leaves Attendance Policies up to Departments, Professors. (2012) the Crimson White. Retrieved May 1, 2013 from http://cw.ua.edu/2012/11/28/ua-leaves-attendance-policies-up-to-departments-professors/

14. Wigley, S. C. (2009). The relationship between attendance and academic performance in further education college A/S psychology students. Journal of Further and Higher Education. 33 (2), 183-190. 